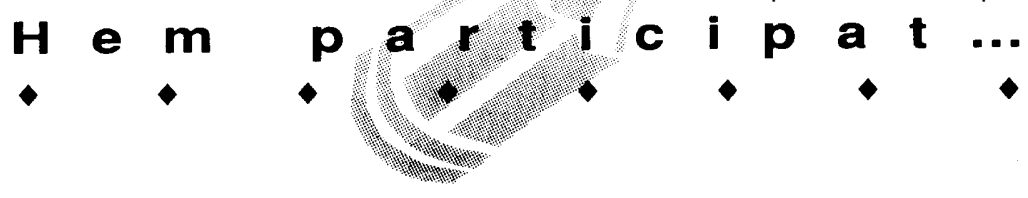

\section{JORNADES DE MOVIMENTS DE RENOVACIÓ PEDAGÒGICA DE CATALUNYA}

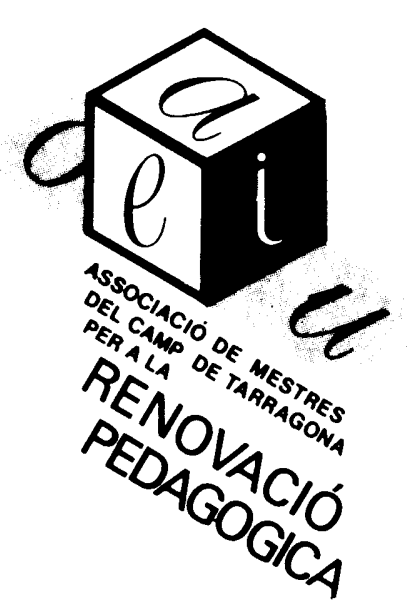

Un total de 400 mestres, pedagogs $i$ pares d'alumnes han participat els dies $6,7 \mathrm{i}$ 8 de novembre a les $I V$ Jornades de Moviments de Renovació Pedagògica de Catalunya, que se celebraren a la localitat de Lloret de Mar, per definir i aprovar un projecte de 100 Mesurespermillorarl'ensenyament. Una de les pretensions més impor-

tants dels mestres és contribuir al fet que la comunitat educativa recuperi el protagonisme en la tasca d'aprofundir en aquesta millora de la qualitat d'ensenyament a Catalunya.

Així, aquest projecte elaborat pels MRPC respon a una triple intencionalitat. D'una banda el document vol atendre la necessitat d'elaborar un programa global d'avenç i millora del sistema educatiu que tingui en compte tots els sectors i nivells possibles d'actuació i que fonamentalment sigui global. La segona intencionalitat respon a una voluntat col.lectiva que permeti identificar, cohesionar ipotenciar les diverses experiències recollides de millora d'ensenyament, i perúltim els mestres pretenen ajustar les seves línies de treball com a MRP al paper que realment volen fer en la transformació qualitativa de l'escola a Catalunya.

Les Jornades van transcórrer en un ambient intens de treball, al mateix temps que desangoixat iil.lusionat. La dinàmica de treball va ser per Blocs, o sigui, deu grups de treball d'entre 25 i 35 persones cadascun. En els grups es van assumir les esmenes $i$ es van debatre els principis de cada Mesura, elaborant unes conclusions i uns acords que van ser llegits al plenari de l'últim dia, diumenge.

A l'acta del plenari es va donar lectura a un "Manifest", que va ser llargament aplaudit per tots els assistents; així mateix es va fer la convocatòria del Primer Congrés de Renovació Pedagògica, que se celebrarà en un termini de tres o quatre anys, que servirà com a punt de trobada, de reflexió i generador de noves propostes

\section{PRIMERES JORNADES DE DIDÀCTICA DE LES MATEMÀTIQUES}

L'Associació de Professors de Matemàtiques de les Comarques Meridionals obrí les portes del Centre de Lectura de Reus, el proppassat 21 de novembre, per a la creació d'unes primeres jornades de treball. S'aconseguí una participació al voltant de les cent setanta persones, amb amics vinguts de Girona i Barcelona. Es mostraren fonamentalment experiències de classe realitzades per diversos grups de professors. Pel matí, alterant el programa inicial: el treball d'anàlisi de l'espai a primària amb figures d'argila de Saül Dalmau, del Grup Almosta. Les imatges dels alumnes treballant encaixos fòren molt interessants. A continuació, una volta cartogràfica per Reus i els seus voltants per treballar longituds, superficies, estimació, itineraris... per acabar constatant com seria el centre de Reus ple d'avellaners. Tot això, a càrrec d'Angel Xifré i Jordi Civit. Quasibé sense descansos - amenitzats amb explicacions de David Barba amb una exposició de materials per a les Matemàtiques a Primària, que durà tot el dia a l'entrada del Centre. Na Cori Bach ens emplenà de formes geomètriques amb gran quantitat d'exemples dels nens i nenes. Amb això el "toc de la mestra" oferia una magistral "tesi viscuda" sobre més de cinquanta diferències individuals dels alumnes i els seus "nivells d'aprofundiment". Després de la dosi generosa d'optimisme escolar, en Claudi Aguadé ens feia reflexionar sobre el que es pot arribar a fer a partir de les "compres per catàleg". La nota de consum i matemàtiques obrí pas a un dinar multitudinari a l'Institut, on es forjava informalment la creació d'una Federació Catalana de Societats de Professors de Matemàtiques amb els brindis de costum. Amb la llengua fora, el Grup Perímetre de Girona, presentava un treball sobre propietats mètriques de poligons des de dos enfocs diferents. Francesc Borrell mostrava "a pas lleuger" un enorme treball d'Estadística realitzat a partir de conèixer el Projecte Teaching Statistics i aplicar-ne moltes idees interessants. Ens resumi el procés de construcció del treball i la seva realització. A continuació Nius Matemàtics a càrrec de Rosa Rius; un material que conjuga les qualitats dels blocs multibase i els àbacs per treballar el càlcul al Cicle Inicial. I abans de concloure, el treball de dos anys de càlcul mental organitzat per Roser Masip i Lluisa Girondo, a l'Escola Pública de Pràctiques. Com es pot veure, una jornada agitada de molt de treball, on el contacte entre els diversos nivells de l'ensenyament fou la nota més impressionant. Els "profes" d'Institut escoltant els mestres i a l'inrevès, amb una atenció extraordinària. 